Article

\title{
The Impact of Cultural Aspects on Building the Smart City Approach: Managing Diversity in Europe (London), North America (New York) and Asia (Singapore)
}

\author{
Dominika Šulyová *[D and Josef Vodák \\ Faculty of Management Science and Informatics, University of Zilina, Univerzitna 8215/1, 01026 Zilina, Slovakia; \\ josef.vodak@fri.uniza.sk \\ * Correspondence: dominika.sulyova@fri.uniza.sk; Tel.: +421-41-513-4022
}

Received: 11 October 2020; Accepted: 12 November 2020; Published: 13 November 2020

\begin{abstract}
One of the main motives for creating this article was to explore the importance of cultural aspects in building smart city approaches. The aim of this article was to obtain answers to three research questions, the answers to which made it possible to identify the elements of multiculturalism that affect the development of smart cities, to find out how multiculturalism affects smart cities and how to manage diversity. The ambition was to create and organize the most important findings into a comprehensive framework. To achieve this goal, secondary analysis methods were used by examining the literature and case studies of best practices from Europe, North America, and Asia. The choice of case studies was conditioned by the placement of smart cities in four global indices (smart city index, Arcadis, IESE and global power index), the existence of a multicultural strategy and elements of successful diversity management, including positive effects and possible limitations. In addition, methods of analysis, comparison and summarization were used. Effective diversity management acts as an accelerator of the sustainable development of smart cities. The results of the analysis of the case studies serve as a basis for recommendations and the creation of a proposed general model, whose task is to simplify the adoption of intelligent concepts, which creates space for the specification of local or cultural conditions of the country. Testing the model in practice is the subject of the following research activities of the authors.
\end{abstract}

Keywords: culture; management; smart cities; diversity; multiculturalism

\section{Introduction}

The purpose of this article is to organize the most important findings of three case studies in the field of interaction between multiculturalism and building smart cities into a comprehensive framework. The aim is to identify key elements that influence the management of diversity depending on the cultural aspects of smart cities in Europe (London), North America (New York) and Asia (Singapore), including the creation of a proposed general model to facilitate the adoption of smart concepts in different cultures. To achieve the set goal, methods of secondary analysis of the literature on smart cities, culture, multiculturalism and their interconnection will be used, including defining key concepts of the researched issues, analysis of three case studies selected on the basis of the results and ranking in smart city indices (selection criteria are specified in Section 3), comparisons and summaries of the results obtained in the discussion section and in the creation of a general model. The analysis of case studies is intended to provide answers to three identified research questions:

- What elements of multiculturalism influence the development of smart cities? 
- How does multiculturalism affect the sustainable development of smart cities?

- How to manage diversity (multiculturalism) appropriately to ensure effective support for the sustainability of smart cities across the world?

Cultural diversity is a key element in the development of any modern society in the twenty-first century. The concept has evolved since ancient times, as multiculturalism is created by people who come from different parts of the world, but currently share the same living or working space. According to Parekh, multiculturalism is the interaction between different cultures in a single space, which should be managed to meet the preferences of all involved [1].

Culture is a natural part of the city's life and development, and thus mediates the heritage for future generations. The heritage of nations is also transferred to urban prosperity and changes in the behavioral and social factors of the perception of individuals, groups, and entire states [2].

The concept of the smart city is currently ambiguous, its description and understanding depend on subjective opinions, attitudes, and personal characteristics, i.e., cultural features. The link between cultural aspects and smart cities is reflected in the UNESCO definition, which considers a smart city to be "a microcosm of cultural aspects that support the sustainability and social development of human capital" $[2,3]$. The terminology of the term smart city in different countries of the world can be found in Table 1.

Table 1. Defining the concept of the smart city in connection with the cultural aspects of different countries.

\begin{tabular}{cc}
\hline Country & Definition \\
\hline Asia [4] & $\begin{array}{c}\text { An agglomeration that can solve various problems by implementing and using the } \\
\text { information and communication technology (ICT) base and manage them } \\
\text { independently through managerial functions so as to achieve an appropriate level of } \\
\text { optimization. }\end{array}$ \\
\hline South Korea [5] & $\begin{array}{c}\text { City where everything can be resolved via mobile phone, including shopping, } \\
\text { education, or healthcare; this ensures higher quality of life, reduced environmental } \\
\text { pollution and protection of scarce resources. }\end{array}$ \\
\hline North America [6] & Flexible, inclusive and collaborative approach for better life of people. \\
\hline Italy [7] & $\begin{array}{c}\text { A transformation of individual interests that will lead to collective benefits in any } \\
\text { selected smart area. }\end{array}$ \\
\hline Spain [7] & $\begin{array}{c}\text { Holistic interactive approach in real time between citizens, companies and the city, } \\
\text { ensuring quality of life, cost-effectiveness, problem solving, and adaptation of needs } \\
\text { based on intelligent technologies. }\end{array}$ \\
\hline Great Britain [7] & $\begin{array}{c}\text { A dynamic concept that is very difficult to define. It is not right to perceive it as a } \\
\text { process, but rather as a sequence of steps leading to sustainability, flexibility and } \\
\text { management of change. }\end{array}$ \\
\hline Lithuania [7] & $\begin{array}{c}\text { The city which can reduce the consumption of natural resources on the principle of } \\
\text { sustainability, provides intelligent services and products to meet the specific needs of } \\
\text { the population, identifies potential opportunities and implements them through } \\
\text { advanced planning and cooperation with stakeholders. }\end{array}$ \\
\hline Denmark [7] & $\begin{array}{c}\text { A platform creating space for smart culture, resources, social services and business } \\
\text { development based on data and IoT technology }\end{array}$ \\
\hline
\end{tabular}

Common elements of the definitions of the term smart city in Table 1 are that the concept is built on the technological basis of information and communication technologies, with the associated effect of a higher quality of life, dynamic development, sustainability and a holistic approach to interaction and cultural differences. The key element of the concept of smart cities is the interaction between sustainable development and multicultural management, i.e., managing cultural differences so as to preserve distinctive cultural identities [8]. According to the General Assembly of the United Nations, sustainable development can meet current needs without adversely affecting the needs of citizens in the future $[9,10]$. The operational definition of a smart city that would be suitable for this research as a reference for the authors is "a city inhabited by a high number of different ethnic groups that 
can cohabitate and generate synergies based on the perception and management of diversity as a competitive advantage of 21st Century Smart Cities".

\section{Literature Review}

\subsection{Building Smart City Approaches}

Every new technology represents a change that needs to be prepared for in advance. The adoption of smart city concepts is realized in the form of a classic project structure with four parts [11]:

- Initiating change;

- Design and preparation phase;

- Testing;

- Putting the final version into practice.

In each phase, there is a different status and approach of residents to the implemented project. The project will result in a reaction that will also affect the city's communication style with the stakeholders. The successful outcome is determined by the quality of management and the applied communication style of the strategic management of the city. In the case of the style of communicating information, managers work on building awareness and support. An inspiring approach favors highlighting the benefits for citizens and recognizing innovation as a driver of urban change and development [11].

Active approach, motivation and participation are invaluable parts of the cities and regions of the future. The city may introduce the latest technologies, but unless they reflect the preferences and opinions of people, the effect will not materialize. By creating communities that support smart city approaches, elements of reciprocity are integrated into life, followed by the effective exchange of resources and knowledge. Between the cooperation of a group of people and the management of the city or region, there is a relationship that is reinforced by education and chosen teaching methods $[12,13]$. The paradigm of the world's smart cities is the primary focus of the data. While data collection is a necessary process, the assignment of data content and in particular the focus on the human factor should not be forgotten [14]. The basic motivation for the proper management of any area of a smart city is to provide its citizens with a people-oriented model that acknowledges and specifies the distinctive characteristics of culture, stakeholder satisfaction and generally accepted and applied equality [14].

\subsection{Interaction between Multiculturalism and Building Smart City Concepts}

Culture is one of the key elements in the sustainable development of smart cities concepts. Legislation, financial and time predispositions or key performance indicators (KPI) monitoring often represent constraints for dynamic, adaptable, flexible, and innovative smart city projects. Multiculturalism is also greatly influenced by the expectations of all smart cities' stakeholders. The current approach to these aspects is determined by the phenomenon of preferred decentralization of strategic management of multicultural cities. Decentralization supports the use of local conditions and specifics, but reduces the degree of communication between the operational, tactical, and strategic levels of cities. The solution is the participation of all stakeholders (private, public sector and citizens) in decision-making processes in smart cities [3].

\section{Culture as a Constant Force for Sustainable Development of Smart Cities}

Sustainable urban development can be achieved through visions and models that are culturally oriented and accept diversity as an advantage. The concept of culture is still poorly understood in the twenty-first century and even underestimated. In 1996, the term was seen as an element of improving people's quality of life, linked to local urban development, sustainability and equality of citizens, regardless of their ethnic group, and thus promoting diversity [3]. In 2014, the Global Taskforce 
of Local and Regional Governments defined culture as an essential element of the sustainability of smart cities, which should be built on centrist-oriented models. Urban multiculturalism generates an integrated and holistic approach to governance, thereby developing creativity, diversity, cultural heritage, awareness, and knowledge for future generations [3]. The interactive relationship between multiculturalism and holistic management of smart cities is misunderstood, and this creates conceptual myths and operational challenges in the researched issues [3]. The first myth states that sustainable urban development must respect current culture and its values must remain unchanged. The opinions and values of a group of people are more important than those of one person. The counterargument is the Declaration of Human Rights of 1948, which states that culture is one of the human rights that belong to each person individually, and cultural practices are modified to suit all citizens and ethnic groups. The second myth perceives culture and multiculturalism as an obstacle to building sustainable smart cities. According to UNESCO, culture played a role and supported the development of the first cities. The claim that culture is fixed in time is myth number three. Historical developments over time clearly argue that values, culture, and diversity are flexible and dynamically evolving. The fourth myth states that culture is a luxurious element that not everyone can afford. Meyer-Bish takes the opposite view, arguing that culture is a part of human dignity, and therefore it is owned by every person in the world without distinction. The last myth perceives culture only from a market perspective. Currently, however, culture influences not only the economic and market environment, but also cities, regions, and the state as a whole. Beatley argues that cultural diversity creates a creative space for the involvement of all stakeholders in the planning, decision-making and implementation process of building and developing smart city concepts with a positive impact on people and the planet [3]. Operational challenges standing in the way of multiculturalism according to UNESCO are [3]:

- Legislation;

- Misunderstanding of the concept of culture;

- Perception of diversity as a source of conflict and not a competitive advantage;

- Challenging evaluation of a cultural element, which is difficult to measure;

- Insufficient stakeholder participation.

The benefits of multiculturalism in connection with the building of smart city concepts according to UNESCO are [3]:

- Integrated approaches to social inclusion;

- Support for the economic growth of the city;

- Integration of positives for smart areas such as mobility, housing, environment, people, etc.;

- Sustainable development and growth;

- Building knowledge databases, communities;

- Promoting creativity, diversity, management, and decision-making.

According to UNESCO experts, smart city management should build interactions on the principles of multiculturalism as follows [3]:

- Clearly defined objectives and priorities;

- Planning, organizing, designing, and monitoring programs and policies for research areas;

- Creating infrastructure and frameworks based on creativity, cultural heritage, and diversity management;

- Centrist-oriented models for the population, their views, expectations, and values;

- Smart city implementation models should be integrated with culture in connection with the sustainable development of the smart city.

\section{Materials and Methods}

The case studies and research results discussed in this article were selected on the basis of the following criteria: 
- Leading position in the ranking of smart cities according to world indices (Table 2);

- Implemented multicultural management strategy;

- Key elements for successful diversity management, including positive effects and possible limitations.

Table 2. Ranking smart cities according to world indices.

\begin{tabular}{ccccc}
\hline \multirow{2}{*}{ Ranking } & \multicolumn{4}{c}{ Index } \\
\cline { 2 - 5 } & Smart City Index & IESE Cities in & ARCADIS Sustainable & $\begin{array}{c}\text { Global Power City } \\
\text { Index 2019 } \\
\end{array}$ \\
& $\mathbf{2 0 1 9}$ & Motion Index 2019 & Cities Index 2018 & {$[18]$} \\
\hline 1 & Singapore & London & London & London \\
\hline 2 & Zürich & New York & Stockholm & New York \\
\hline 3 & Oslo & Amsterdam & Edinburgh & Tokyo \\
\hline
\end{tabular}

From the geographical area of Europe, the city of London won first place in three of the four indices. The capital of the United Kingdom reached the top of the Global Power City Index 2019 in the ranking of cultural diversity, which has an impact on the behavioral, social, managerial and technical aspects of implementing smart city approaches in practice.

In the Smart City Index of 2019, Singapore was placed at the leading position and represents best practices for smart cities in East Asia. In the North America region, the city of New York is perceived as a representative of best practices. In the discussion part (Section 5), methods for summarizing the analyzed findings were used, including a comparison of case studies from London, New York and Singapore and the implications with respect to the created model, including a summary of its benefits and its implementation limitations.

\section{Results}

\subsection{Diversity Management in London}

London is one of the cities with the greatest diversity in the twenty-first century. The people of London belong to 50 community groups and speak more than 300 languages. In 2001, social and cultural unrest arose that needed to be resolved. In its strategy for managing the cultural differentiation of citizens, the city council has set itself the objective of creating a uniform standard of recognized British values and, according to the values, implementing a reform of management structures at the local level. The whole process is dynamic and constantly subject to ongoing changes. In the previous time period, a critical success factor for the effective administration of various areas has been the management of cultural diversity through the organization of imperial conferences in the twentieth century. At these meetings, relations in individual colonies were discussed. Today, the tradition continues through a community of nations involving 54 countries from around the world, representing 2.4 trillion people with different cultures but the same goals $[19,20]$. A common aspect for the integration of foreigners in London is not the sharing of values, but rather the collective future in which every British citizen should participate [21]. The results of the study point to three elements that build cultural intelligence, namely the perception of diversity as a national advantage, a liberalist approach promoting openness, and interculturalism [21].

\subsubsection{Perception of Diversity as an Advantage}

Historical experiences with colonization have changed the thinking of people in Britain and their attitudes towards foreigners. They see new people as an opportunity to support the country and not a threat. Similarly, countries such as the United States and Canada have responded positively to the influx of immigrants traveling for work. Foreigners are integrated into a national identity that promotes the heterogeneity, economic, social, political, and cultural side of society [21]. Multiculturalism is also 
evident in the strategic management of the city; the mayor of London is Sadiq Khan. Through his credibility, integrity, motives, competence, and the results of his work, he has gained the trust of the citizens who have elected him to a leading position in strategic management [21].

\subsubsection{Liberalism}

People's openness to change is essential for embracing innovation, technology, and smart city concepts. The more a person prefers a liberalist approach to life, the higher their curiosity, multiculturalism, and tolerance [21].

\subsubsection{Interculturalism}

In Britain, there are no boundaries between national and civic culture, resulting in straightforward communication, cooperation, and support for the globalization aspect [21].

\subsection{Managing Diversity in New York}

Multiculturalism in New York is supported by key elements that promote cultural diversity, assertive and adaptable management, which see diversity as an asset for the sustainable development of smart cities in New York, implemented under the PlaNYC 2030 plan, suitable state support, and an effort to curb the high level of crime that reduces the quality of life of citizens [22]. New York, along with cities such as London and Paris, has the largest number of migrants, whose integration into local communities is managed by strategic management through lifelong learning and positive acceptance of the diversity of people of all ages, community building and the following cultural strategies [22]:

- Raise awareness about other cultures, customs, and traditions;

- Integrate foreigners into local communities;

- Work together to improve their level of English;

- Perceive differences between people as an advantage from an early age in the form of an educational process.

\subsection{Diversity Management in Singapore}

In order to implement the necessary changes and identify with the new concept of smart Singapore, the inhabitants had to change their behavior and their usual lifestyle. The change in thinking, education, and preparation for life in a smart city has been implemented in Singapore from children at an early age through the so-called "Theory of change". The educational transformation process consists of smart city development programs and subsystems such as government, finance, data, standards, resource capacity, stakeholder commitment, communities, and cultural impact on the adoption of multiculturalism (i.e., the inputs) [23].

The outputs concern the system (quality of life, equality of individual population groups, environmental sustainability, and overall efficiency of implemented activities) and families (support and participation in the implementation of the smart city vision). Smart city software applications for sustainable development have been developed in four official languages to be understood by all age and ethnic groups of the population [23]. A case study from the city of Singapore calls for the importance of educating and preparing children for diversity and intelligent aspects in agglomerations from an early age. Any positive or negative reaction will affect the whole diversity management system, which works on the principle of the classical transformation process. The quality of the outputs is clearly conditioned by the level of inputs [23].

\section{Discussion}

Relevant data were obtained from the conducted secondary research, through which it is possible to answer the three set research questions. 


\subsection{What Elements of Multiculturalism Influence the Development of Smart Cities?}

Comparing three case studies of multicultural smart cities, i.e., London, New York and Singapore representing Europe, North America and Asia, respectively, seven elements have been identified that influence the development of smart cities: cultural awareness, diversity as a competitive advantage, education, management style, community liberalism, differentiation, and systemic approach, all listed in more detail in the following Table 3.

Table 3. Common elements of diversity management in London, New York, and Singapore (authors' processing according to the results of the three case studies).

\begin{tabular}{cccc}
\hline Elements of Diversity Management & London & New York & Singapore \\
\hline $\begin{array}{c}\text { Cultural awareness is the key element in managing diversity. } \\
\text { The ability to manage diversity can be seen as a } \\
\text { competitive advantage. }\end{array}$ & $\mathrm{x}$ & $\mathrm{x}$ & $\mathrm{x}$ \\
\hline $\begin{array}{c}\text { Education and mentoring are important elements of } \\
\text { diversity management. }\end{array}$ & $\mathrm{x}$ & $\mathrm{x}$ & $\mathrm{x}$ \\
\hline $\begin{array}{c}\text { The prediction of cultural conflicts should be dealt with by the } \\
\text { strategic management of the city. }\end{array}$ & $\mathrm{x}$ & $\mathrm{x}$ \\
\hline $\begin{array}{c}\text { The establishment of community centers should be supported } \\
\text { by all stakeholders in liberalistic way. }\end{array}$ & $\mathrm{x}$ & $\mathrm{x}$ \\
\hline $\begin{array}{c}\text { Smart City concepts should be implemented globally, } \\
\text { but specified according to the local cultural conditions } \\
\text { and requirements. }\end{array}$ & $\mathrm{x}$ & $\mathrm{x}$ \\
\hline $\begin{array}{c}\text { Cultural diversity is a system that works on the principle of } \\
\text { the transformation process of inputs to outputs. }\end{array}$ & & $\mathrm{x}$ \\
\hline
\end{tabular}

Common multicultural elements that have a positive impact on diversity management, including sustainable development, are awareness-raising, perception of diversity as a competitive advantage, education about multicultural values, community building based on liberalism, and adapting smart city concepts to local culture and ethnic specifics. A different approach is taken by New York, where they highlight the importance of assertive and flexible management, which should anticipate cultural conflicts. Singapore prefers the perception and management of cultural diversity through a systems approach in the form of a transformation process. Five logical elements of smart cities' multiculturalism were generated by a logical reduction:

- Awareness;

- Diversity as a competitive advantage;

- Education, liberal communities;

- $\quad$ Flexibility.

\subsection{How Does Multiculturalism Affect the Sustainable Development of Smart Cities?}

The following Table 4 describes three aspects that affect the sustainable development of smart cities. All three analyzed cities achieve multicultural status according to global city assessments in 2018 and 2019. The impact of multiculturalism on the development of sustainability is reflected in the placement of the global smart cities' rankings (Table 2), where London and Singapore are at the top and New York ranks second.

The plans of multicultural management are based on the following elements: the perception of diversity as a competitive advantage, liberalism, interculturalism and education in connection with the positive acceptance of change. The plans are harmonized with smart city development programs, such as PlaNYC 2030 in New York. 
Table 4. Three aspects that affect the sustainable development of smart cities.

\begin{tabular}{cccc}
\hline Aspects & London & New York & Singapore \\
\hline Multicultural status [24] & Yes & Yes & Yes \\
\hline $\begin{array}{c}\text { Efficiency of Smart City } \\
\text { development [15-18] }\end{array}$ & $\begin{array}{c}\text { 1. place in IESE, Arcadis, } \\
\text { Global power indexes }\end{array}$ & $\begin{array}{c}\text { 2. place in IESE, Global } \\
\text { Power indexes }\end{array}$ & $\begin{array}{c}\text { 1. place in Smart City } \\
\text { Index 2019 }\end{array}$ \\
\hline $\begin{array}{c}\text { Multicultural management } \\
\text { plan [21-23] }\end{array}$ & $\begin{array}{c}\text { Diversity as an } \\
\text { advantage, liberalism, } \\
\text { interculturalism }\end{array}$ & $\begin{array}{c}\text { Diversity as an } \\
\text { advantage, } \\
\text { PlanNYC2030, education }\end{array}$ & $\begin{array}{c}\text { Diversity as an } \\
\text { advantage, theory of } \\
\text { change, education }\end{array}$ \\
\hline
\end{tabular}

\subsection{How to Manage Diversity (Multiculturalism) Appropriately to Ensure Effective Support for the} Sustainability of Smart Cities in the World?

The answers to the previous two research questions create the preconditions for answering the third research question. In Figure 1 below, we identify and schematically outline the key elements needed to create a general model of diversity management to support the interactive relationship between multiculturalism and building smart cities (Figure 1).

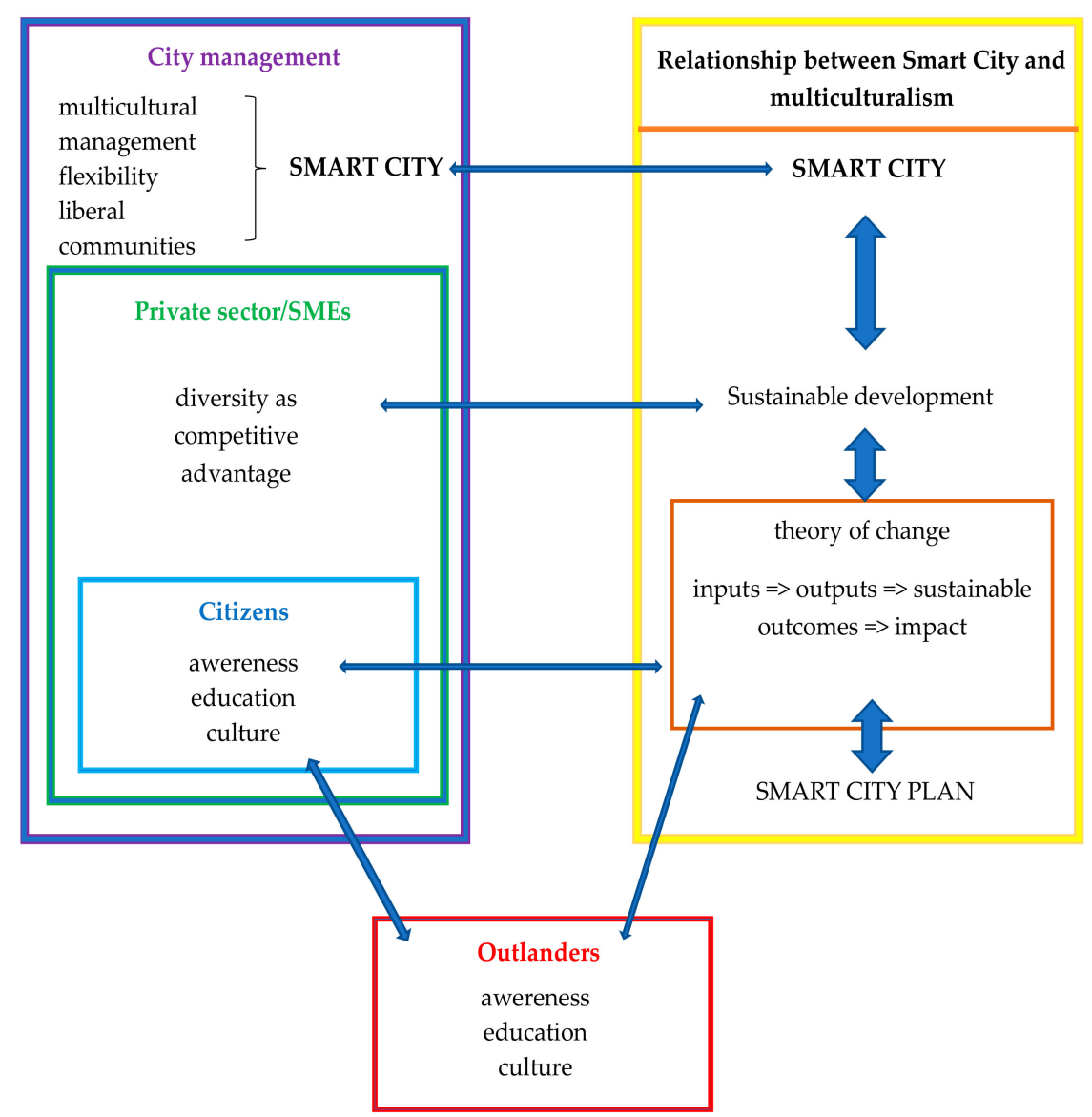

Figure 1. The general diversity management model to support the interactive relationship between multiculturalism and sustainable smart city development (authors' processing according to the results of the analysis of the case studies of London, New York, and Singapore) [21-23].

The basic element of the recommended model in Figure 1 are the inhabitants of a smart city, as it is important to build awareness of other cultures and nations through education from an early age, thereby deepening and connecting the values of their culture with other world cultures. An external element that affects multiculturalism are foreigners who, similar to citizens, have their own systems of culture and values, but if they want to live in another city and country, they need to build awareness about other cultures and learn the language or another suitable communication method. In this 
way, citizens and foreigners actively support positive change in the form of a theory of change that works on the principles of the transformation process. The primary sector should see the diversity of its employees as a competitive advantage, thereby promoting a positive relationship between multiculturalism and sustainable development. City management should manage diversity on the basis of the elements already mentioned, including support for the creation of liberal communities and flexibility. A central element for building the concepts of the smart multicultural city is the development plan, which should be accepted by all stakeholders through the theory of change, which has a positive effect on the development of the city and the whole smart city concept. The double-headed arrows in Figure 1 show the feedback between the individual elements. The main benefits of the created general model are:

- Promoting multiculturalism, lifelong learning, awareness;

- Building liberal communities;

- Participation of all stakeholders;

- Feedback for continuous improvement of concepts and sustainability of the smart city;

- Pointing out the key elements of diversity management and their impact on the process of implementing intelligent concepts for any city, of course, taking into account local, cultural and other specifics.

Limitations of the general diversity management model, built to support the interactive relationship between multiculturalism and building smart cities, include:

- The need to adapt the model to regional and cultural specifics;

- The importance of testing and verifying the functions of the model in practice.

Finally, the secondary analysis and the creation of a general implementation model show that multiculturalism has a positive effect on sustainable urban development. However, cultural differences should not strictly separate one country from another but form a bridge between different nationalities.

\section{Conclusions}

The purpose and goals of this article were achieved through the results of the secondary analysis. Relevant answers to the three research questions were obtained. Key elements of multiculturalism that affect the development of smart cities include:

- Awareness;

- Diversity as a competitive advantage;

- Education;

- Liberal communities;

- Flexibility.

The main findings of this article are as follows:

- Multiculturalism has a positive effect on the development of sustainability and for building smart cities;

- Multiculturalism needs to be managed through early childhood education;

- Building awareness of other cultures;

- Positive acceptance of change;

- Perception of diversity as a competitive advantage in personal and professional lives;

- Strategic city management should support flexibility and the building of liberal communities;

- Multicultural management supports effective smart city plans that are easier to adopt through a theory of change that supports sustainable development and overall smart city concepts. 
These points are perceived by the authors as recommendations for the effective implementation of a smart city based on multiculturalism and diversity management. If the recommendations are implemented in accordance with all smart city concepts outlined, all stakeholders will embrace change more easily and more effectively in the long term and thus will contribute to a better future and adaptation to the new generation. To gain these benefits, the proposed diversity management model can be used to support the interactive relationship between multiculturalism and building smart cities. Testing of the proposed model in practice is part of the following research activities in the future.

Author Contributions: J.V. coordinated the research, D.Š. analyzed the data, J.V. and D.Š. wrote the paper, all authors built the conceptual framework. All authors have read and agreed to the published version of the manuscript.

Funding: This research received no external funding.

Conflicts of Interest: The authors declare no conflict of interest.

\section{References}

1. Sarraf, M. Spatiality of Multiculturalism. Ph.D. Thesis, KTH Royal Institute of Technology, Stockholm, Sweden, 2015. Available online: https://www.diva-portal.org/smash/get/diva2:813394/FULLTEXT01.pdf (accessed on 28 October 2020).

2. Allam, Z.; Newman, P. Redefining the Smart City: Culture, Metabolism and Governence. Smart Cities 2018, 1, 2. [CrossRef]

3. UNESCO. Culture Urban Future. Global report on Culture for Sustainable Urban Development; The United Nations Educational, Scientific and Cultural Organization: Paris, France, 2016; Available online: http: //unesdoc.unesco.org/images/0024/002459/245999e.pdf (accessed on 28 October 2020).

4. OECD. Smart Cities and Inclusive Growth. Available online: https://www.oecd.org/cfe/cities/OECD_Policy_ Paper_Smart_Cities_and_Inclusive_Growth.pdf (accessed on 27 July 2020).

5. Ministry of Land, Infrastructure and Transport. Korean Smart Cities. Available online: https://smartcity.go. kr/wp-content/uploads/2019/08/Smart-city-broschureENGLISH.pdf (accessed on 5 September 2020).

6. Future Cities Canada. Getting to the Open Smart City. Discussion Paper. October 2018. Available online: https://futurecitiescanada.ca/downloads/2018/Getting_to_Open_Smart_City.pdf (accessed on 5 September 2020).

7. Enel, X. Smart City: The Italian Cities of the Future. Available online: https://www.enelx.com/it/en/resources/ stories/2019/06/smart-city-cities-italian-virtuous (accessed on 5 September 2020).

8. Civil Service India. Multicultural Management. Available online: https://www.civilserviceindia.com/subject/ Management/notes/multicultural-management.html (accessed on 28 October 2020).

9. Emas, R. Brief for GSDR 2015. The Concept of Sustainable Development: Definition and Defining Principles, Florida International University. 2015. Available online: https://sustainabledevelopment.un.org/content/ documents/5839GSDR\%202015_SD_concept_definiton_rev.pdf (accessed on 28 October 2020).

10. Schipper, R.P.J.R.; Silvius, A.J.G. Characteristics of Smart Sustainable City Development: Implications for Project Management. Smart Cities 2018, 1, 5. [CrossRef]

11. Tallinger, A. The 'People' Side of Implementations: Change vs. Readiness vs. Culture. Available online: https://www.impact-advisors.com/it-operations/the-people-side-of-implementations-change-vsreadiness-vs-culture/ (accessed on 27 July 2020).

12. Cleveland, M.; Cleveland, S. Building Engaged Communities-A Collaborative Leadership Approach. Smart Cities 2018, 1, 9. [CrossRef]

13. Koman, G.; Kubina, M.; Holubcik, M.; Soviar, J. Possibilities of Application a Big Data in the Company Innovation Process. Commun. Comput. Inf. Sci. 2018, 877, 646-657.

14. Xu, H.; Geng, X. People-Centric Intelligence for Smart Cities. Smart Cities 2019, 2, 10. [CrossRef]

15. IMD. IMD and SUTD's Unique Ranking Shows Importance of Citizens' Needs in Policymaking. Available online: https://www.imd.org/smart-city-observatory/smart-city-index/ (accessed on 19 July 2020).

16. ARCADIS. Citizen Centric Cities. The Sustainable Cities Index. 2018. Available online: https://www.arcadis.com/media/1/D/5/\%7B1D5AE7E2-A348-4B6E-B1D7-6D94FA7D7567\%7DSustainable_ Cities_Index_2018_Arcadis.pdf (accessed on 19 July 2020). 
17. IESE. IESE Cities in Motion Index. 2019. Available online: https://blog.iese.edu/cities-challenges-andmanagement/2019/05/10/iese-cities-in-motion-index-2019/ (accessed on 19 July 2020).

18. Institute for Urban Strategies. The Mori Memorial Foundation. Global Power City Index. 2019. Available online: http://mori-m-foundation.or.jp/english/ius2/gpci2/index.shtml (accessed on 19 July 2020).

19. State Library Victoria. British colonial history. Available online: https://www.slv.vic.gov.au/search-discover/ explore-collections-theme/british-colonial-history (accessed on 6 September 2020).

20. The Commonwealth. 54 Countries Working Together for Prosperity, Democracy and Peace. Available online: https://thecommonwealth.org/ (accessed on 6 September 2020).

21. Wood, P.; Landry, C.; Bloomfield, J. Cultural Diversity in Britain, 1st ed.; Joseph Rowntree Foundation: York, UK, 2006.

22. Clark, G. Managing Diversity, Integration and Inclusion in OpenCities; British Council: Madrid, Spain, 2010; Available online: https:/www.alnap.org/system/files/content/resource/files/main/managing-diversity.pdf (accessed on 28 October 2020).

23. Bull, R.; Bautista, A.; Salleh, H.; Karuppiah, N. Evolving a Harmonized Hybrid System of ECEC: A Careful Balacing Act. A Case Study of the Singapore Early Childhood Education and Care System. Teachers Collage 2018. Available online: http://ncee.org/wp-content/uploads/2019/03/EA-Singapore-Case-Study-03-26-19.pdf (accessed on 19 July 2020).

24. Pardo, C. The 10 Most Multicultural Cities in the World. Available online: https://www.topics.plusrelocation. com/post/102fre3/the-10-most-multicultural-cities-in-the-world (accessed on 28 October 2020).

Publisher's Note: MDPI stays neutral with regard to jurisdictional claims in published maps and institutional affiliations.

(C) 2020 by the authors. Licensee MDPI, Basel, Switzerland. This article is an open access article distributed under the terms and conditions of the Creative Commons Attribution (CC BY) license (http://creativecommons.org/licenses/by/4.0/). 